\title{
Fabrication and Characterization of Nano- Hydroxyapatitel Chitosan Biocomposites with and without Citric Acid Addition
}

\author{
K. R. Mohamed ${ }^{\#}$, Aida A. Salama* and Zenab M.I. El- \\ Rashidy \\ Biomaterials Dept., National Research Centre and *Biophysics \\ Dept., Faculty of Science, Al-Azhar University, Cairo, Egypt.
}

\begin{abstract}
R IOCOMPOSITES composed of carbonated apatite and chitosan in B the presence or absence of citric acid were fabricated through a co-precipitation method. The prepared biocomposites were characterized by Fourier transformed infrared spectroscopy (FT-IR), $\mathrm{X}$ - ray diffraction (XRD), Thermo gravimetric analysis (TGA), Transmission electron microscopy (TEM), and Scanning electron microscopy (SEM). The results proved that the presence of citric acid in the composite accelerated HA formation and reduced its particle size. Also, the compressive strength increased for HA/chitosan composite compared to HA alone and more increased with addition of citric acid which enhanced the binding strength between HA particles. The HA/chitosan composite with ratio $70 \% \mathrm{HA}$ and $30 \%$ chitosan, especially with citric acid, may be promising for bone grafting and bone tissue engineering applications.
\end{abstract}

Keywords: Apatite, Chitosan, Biocomposites, Citric acid and TEM.

Hydroxyapatite $\left(\mathrm{Ca}_{10}\left(\mathrm{PO}_{4}\right)_{6}(\mathrm{OH})_{2}\right)$ has been used for orthopedic and dental implants because it has a similar chemical composition and structure to the mineral phase of human bone ${ }^{(1)}$. Because of its low fracture toughness, hardness and brittleness, HA can't serve as a bulk implant material under the high physiological loading conditions ${ }^{(2)}$. Carbonate apatite has been used as a biocompatible and osteoconductive substitute in the field of hard tissue repair and regeneration, especially nano-carbonate apatite elicits cell-biomaterial interactions because of its better resorption and close surface contact with the surrounding tissue ${ }^{(3)}$.

Therefore, novel composites of hydroxyapatite and organic polymers have become of great interest to compensate the weak mechanical points of hydroxyapatite $^{(4)}$. Chitosan possesses biocompatible, biodegradable ${ }^{(5)}$, and antibacterial properties ${ }^{(6)}$. In addition, chitosan is flexible and has a high resistance up heating due to the intra- molecular hydrogen bonds formed between hydroxyl and amino groups ${ }^{(4)}$. Chitosan has been used as substitute for bone ${ }^{(7)}$, cartilage ${ }^{(8)}$ and nerve ${ }^{(6)}$.

\#Corresponding author: Kh_rezk1966@yahoo.com 
Citric acid $\left(\mathrm{C}_{6} \mathrm{H}_{8} \mathrm{O}_{7}\right)$, which has a hydroxyl and three carboxyl groups in its molecule, is found in bone in the form of citrate in $0.9 \mathrm{wt} \%{ }^{(9)}$. Citric acid plays an important role in citric acid cycle of humans. In general, chitosan and organic acid forms a chitosan-organic acid complex ${ }^{(4)}$. Hydroxyapatite/ polymer composites have osteoconductivity due to the presence of hydroxyapatite ${ }^{(10)}$. A composite biomaterial of HA and chitosan increased osteoconductivity and biodegradation together with sufficient mechanical strength for orthopedic use ${ }^{(11)}$.

The objective of the present work is to prepare and characterize the nano HA/ chitosan polymeric composites in the presence and absence of citric acid. The compressive strength of the composites was also measured to evaluate the role of citric acid in the composite strength.

\section{Materials}

\section{Materials and Methods}

The starting materials for preparing hydroxyapatite (HA) are calcium hydroxide $\left(\mathrm{Ca}(\mathrm{OH})_{2}\right)$ and orthophosphoric acid $\left(85 \% \quad \mathrm{H}_{3} \mathrm{PO}_{4}\right)$ (Laboratory Rasayan). Other materials were chitosan polymer (viscosity $800 \mathrm{cps}$ ) with high molecular weight $\left(\mathrm{M}_{\mathrm{r}}=600,000\right)$ and deacetylation of $85 \%$ (Sigma-Aldrich), anhydrous citric acid (Morgan Chemical Ind. Co., Egypt), ethanol and 96\% acetic acid (EL-Nasr Pharmaceutical Co., Egypt).

\section{Methods \\ Preparation \\ Preparation of hydroxyapatite/chitosan composites: The compositions of hydroxyapatite/chitosan composites were given in Table 1. The Notations of the prepared composites were mentioned in Table 2. Preparation of HAC1 composite with weight ratio composition [(HA: chitosan (80:20)] was mentioned as follows: The chitosan solution with a concentration of $4 \%$ was prepared by dissolving chitosan $(4 \mathrm{~g})$ into $2 \%$ acetic acid with stirring for $5 \mathrm{hr}$ to get a perfectly transparent solution. Afterwards, this solution was mixed with $9.37 \%$ solution of $\mathrm{H}_{3} \mathrm{PO}_{4}$ and dropped slowly onto the $11.81 \%$ ethanol solution of $\mathrm{Ca}$ $(\mathrm{OH})_{2}$ with vigorous stirring, kept for $24 \mathrm{hr}$ after dropping and then the obtained paste was aged for another $24 \mathrm{hr}$. Finally, the precipitate was filtered, washed with distilled water to remove the excess of $\mathrm{NaOH}$ solution and then dried in a vacuum oven at $70^{\circ} \mathrm{C}$.}

Preparation of hydroxyapatite/chitosan/citric acid composites: Chitosan was dissolved in $0.2 \mathrm{M}$ citric acid instead of $2 \%$ acetic acid to prepare chitosan solution. Then, hydroxyapatite/chitosan/citric acid composites with different weight ratios of hydroxyapatite and chitosan polymer were fabricated by the same method of hydroxyapatite/chitosan composites preparation as in Table 1. 
TABLE 1. The Compositions of hydroxyapatite/chitosan composites.

\begin{tabular}{|c|c|c|c|c|}
\hline Samples & $\begin{array}{c}\text { HA/chitosan } \\
\text { (weight ratio) }\end{array}$ & $\begin{array}{c}\text { Ca }(\mathbf{O H})_{\mathbf{2}} \\
(\mathbf{g})\end{array}$ & $\begin{array}{c}\mathbf{H}_{\mathbf{3}} \mathbf{P O}_{\mathbf{4}} \\
(\mathbf{g})\end{array}$ & $\begin{array}{c}\text { Chitosan } \\
(\mathbf{g})\end{array}$ \\
\hline HA powder & $100 / 0$ & 14.76 & 11.71 & -- \\
\hline HAC1 comp. & $80 / 20$ & 11.81 & 9.37 & 4.00 \\
\hline HAC2 comp. & $70 / 30$ & 10.33 & 8.20 & 6.00 \\
\hline HAC3 comp. & $60 / 40$ & 8.86 & 7.03 & 8.00 \\
\hline HAC4 comp. & $50 / 50$ & 7.38 & 5.86 & 10.00 \\
\hline HAC5 comp. & $20 / 80$ & 2.95 & 2.34 & 16.00 \\
\hline
\end{tabular}

TABLE 2. The notations of hydroxyapatite/chitosan composites.

\begin{tabular}{|c|c|c|c|c|}
\hline HAC1 comp. & HAC2 comp. & HAC3 comp. & HAC4 comp. & HAC5 comp. \\
\hline $80 \% \mathrm{HA} / 20 \%$ & $70 \% \mathrm{HA} / 3 \%$ & $60 \% \mathrm{HA} / 40 \%$ & $50 \% \mathrm{HA} / 50 \%$ & $40 \% \mathrm{HA} / 60 \%$ \\
chitosan & chitosan & chitosan & chitosan & chitosan \\
composite & composite & composite & composite & composite \\
\hline
\end{tabular}

\section{Sample characterization}

The FT-IR spectrum was assessed in the range of 400 to $4000 \mathrm{~cm}^{-1}$ using Jasco, FT/IR 300 E, Fourier Transform Infrared Spectrometer, Serial No. 4140109, and Japan. The phase purity of samples was examined by X-ray diffractometer (Philips P.W: 1730) with $\mathrm{Cu} \mathrm{K} \mathrm{K}_{\alpha}$ target, $\mathrm{C} / \mathrm{S} 1000$. The thermo-gravimetric analysis of the samples was carried out using Shimadu TGA-50H under $\mathrm{N}_{2}$ flow over rate 30 $\mathrm{ml} / \mathrm{min}$, Rate: $10 \% \mathrm{~min}$. The particle size of the HA powder for the composites was examined using the transmission electron microscope unit (JEM-1230 Japan), $0.2 \mathrm{~nm}$ Resolution, $600 \mathrm{KX}$ Magnification. The morphology of the prepared samples was examined by means of SEM, JXA 840A Electron Probe Microanalyzer (JEOL, Japan). The compressive strength was measured using Instron $5500 \mathrm{R}$ the universal testing machine, USA; at a cross head speed of 1 $\mathrm{mm} / \mathrm{min}$ and load cell was $10 \mathrm{KN}$. The average value was taken of three samples to ensure the results and size of the measured samples was $1 \mathrm{~cm}$ diameter $\times 1 \mathrm{~cm}$ thickness and shape of the sample was having a cylindrical shape.

\section{FT-IR analysis}

\section{Results and Discussions}

Figure 1 represents the FT-IR spectra of HA, chitosan and their composites. The bands of HA appeared at 3641 and $3440 \mathrm{~cm}^{-1}$ in the HA powder and were assigned to the stretching modes of vibration of $\mathrm{OH}$ group. In addition, the bands at 1457, 1460, 1422 and $877 \mathrm{~cm}^{-1}$ also appeared and were assigned to the $\mathrm{CO}_{3}{ }^{2-}$ groups. Also, the characteristic bands for $\mathrm{PO}_{4}{ }^{3-}$ groups were recorded at 1028, 603 and $569 \mathrm{~cm}^{-1}$ in HA powder. Shen et al. ${ }^{(12)}$ proved that the band appeared at $1027 \mathrm{~cm}^{-1}$ which was assigned for the $\mathrm{PO}_{4}{ }^{3-}$ stretching mode. The bands of chitosan in chitosan powder appeared at $3446 \mathrm{~cm}^{-1}$ for $\mathrm{OH}$, at $1652 \mathrm{~cm}^{-1}$ for amide I, at $1550-1540 \mathrm{~cm}^{-1}$ for amide II, at $1118 \mathrm{~cm}^{-1}$ for the C-O and at 2921 and $1458 \mathrm{~cm}^{-1}$ for the $\mathrm{CH}$ band ${ }^{(13)}$. Figure 1 also shows the FT-IR of HAC composites. The intensity of $\mathrm{HA}$ bands in all $\mathrm{HAC}$ composites such as $\mathrm{OH}$ at 3641,3562 and at $3440 \mathrm{~cm}^{-1}, \mathrm{CO}_{3}{ }^{2-}$ at $1457,1460,1422$ and $877 \mathrm{~cm}^{-1}$ and $\mathrm{PO}_{4}{ }^{3-}$ at 1028,603 and at $569 \mathrm{~cm}^{-1}$ were reduced compared to the original bands in the 
HA powder proving the coating effect, especially in the case of the HAC2 composite. Also, the bands of chitosan in the spectra of HAC composites such as $\mathrm{OH}$ at $3446 \mathrm{~cm}^{-1}, \mathrm{CH}$ at $2921 \mathrm{~cm}^{-1}$ and amide $\mathrm{I}$ at $1652 \mathrm{~cm}^{-1}$ were reduced compared to original polymer denoting interactions through hydrogen bonds as follows: (1) The $\mathrm{OH}$ of HA and chitosan, (2) the calcium of the HA with $\mathrm{OH}$ or amino group of chitosan, (3) the phosphate of the HA with the amino group of chitosan $^{(14)}$.

The FT-IR spectra of HA, chitosan, citric acid and their composites are shown in Fig. 2. The bands appeared for the citric acid powder were $\mathrm{OH}$ at 3500 and $3447 \mathrm{~cm}^{-1}, \mathrm{CH}$ at $2988,1428,1391,1356$ and $1300 \mathrm{~cm}^{-1}, \mathrm{C}-\mathrm{O}$ at 1176,1140 , 1086 and $1086 \mathrm{~cm}^{-1}$ and $\mathrm{C}=\mathrm{O}$ at 1750 and $1702 \mathrm{~cm}^{-1(15)}$. It is clear that there is high reduction in the intensity of the bands in the HAC/citric acid composites compared to the same composites without citric acid proving high coating. Some bands such as $\mathrm{OH}$ at $3446 \mathrm{~cm}^{-1}, \mathrm{CH}$ at $1356 \& 1300 \mathrm{~cm}^{-1}$ and $\mathrm{C}-\mathrm{O}$ at $1052 \mathrm{~cm}^{-1}$ were shifted to $3418,1337,1317$, and 1031, respectively, proving interaction between hydroxyl groups of citric acid, chitosan polymer and HA through hydrogen bonding. Also, citric acid strongly interacted with calcium ions via its $\mathrm{COO}^{-}$groups forming calcium citrate complex.

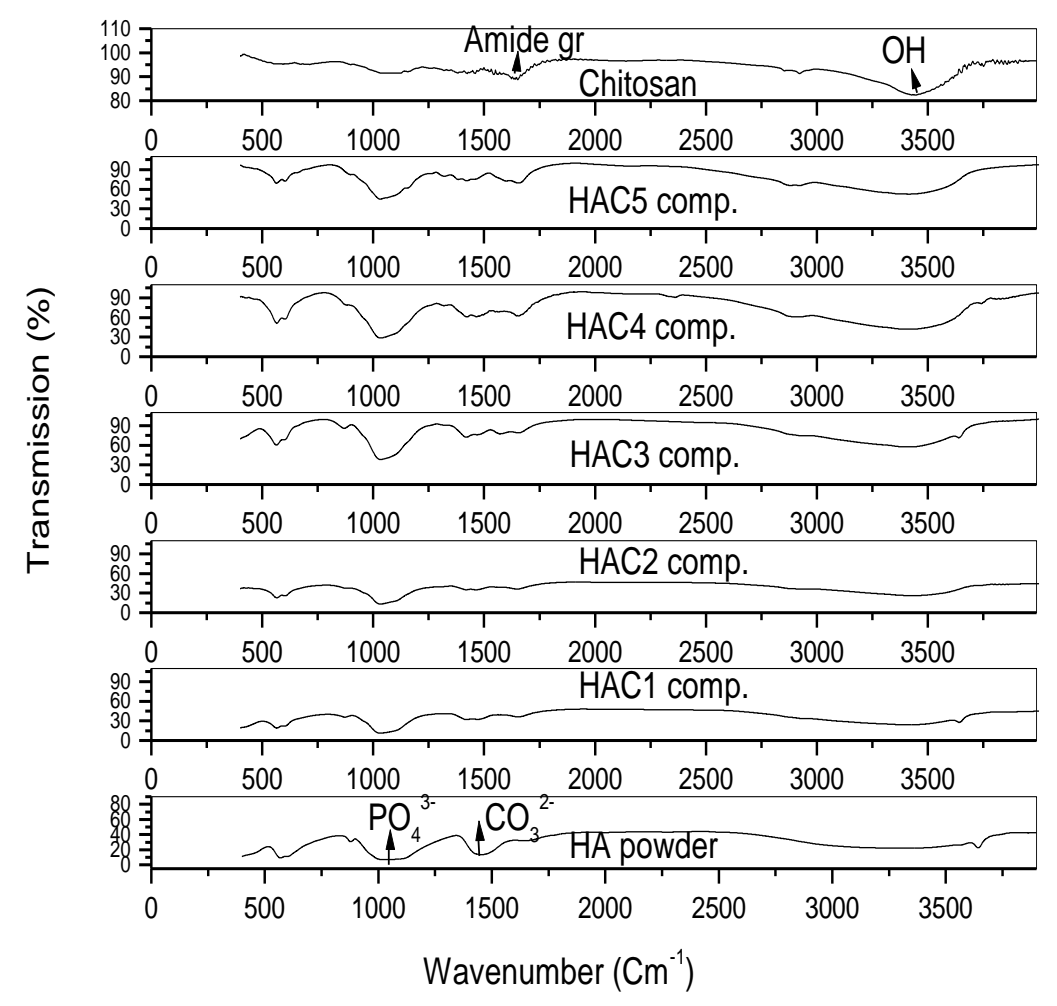

Fig. 1. The FT-IR of HA, chitosan and HAC composites.

Egypt. J. Chem. 55, No. 1 (2012) 


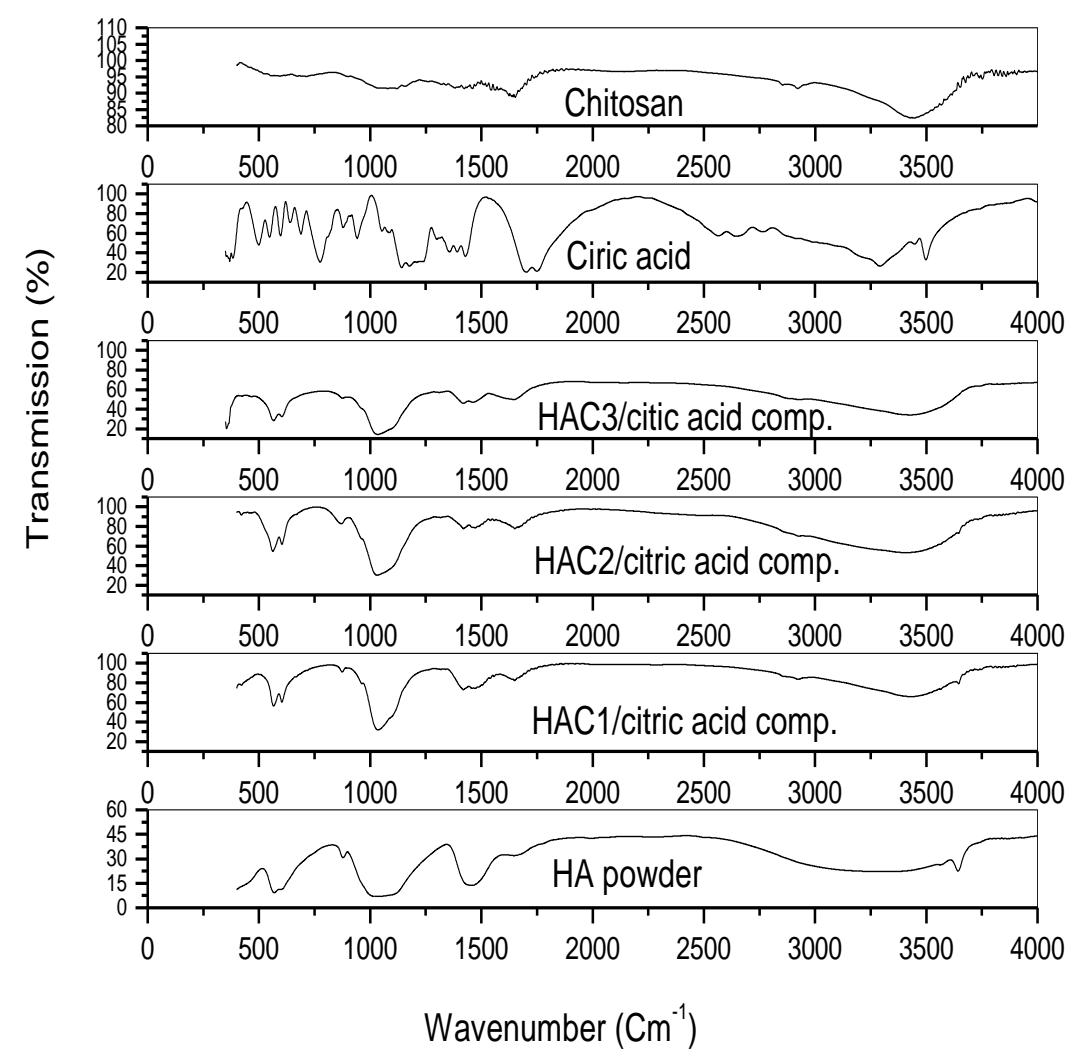

Fig. 2. The FT-IR of HA, chitosan, citric acid and HAC/citric acid composites.

Phase analysis

Figure 3 shows the patterns of HA powder, chitosan and their composites. The spectrum of HA powder has the diffraction peaks of d-spacing $(\AA)$ equal to 4.06, 3.4, 3.1, 2.8, 2.7, 2.6, 1.79, 1.7, 1.48, 1.4 and 1.3 (Card No.9.432). The broadening diffraction peaks from $2 \theta=30-35$ for the prepared HA denote that HA is composed of small crystals and are poorly crystalline ${ }^{(16)}$. The peaks of calcium hydroxide appeared in the prepared HA powder at the d-spacing equal to 4.9, 3.1, 2.6, 1.9, 1.79, 1.68 and 1.4 (Card No.87-0673) proving that part of calcium hydroxide is un-reacted to form further HA particles (Fig. 3). In this domain, Liang et al. ${ }^{(17)}$ reported that the calcium hydroxide promotes the repair of bone tissues by providing rich $\mathrm{Ca}^{2+}$ ions and alkaline environment to deposit the minerals and stimulate calcification enzyme activity of osteoblasts. Several experimental studies have shown that calcium hydroxide may possess antimicrobial ${ }^{(18)}$ and anti-inflammatory properties ${ }^{(19)}$. Therefore, the presence of calcium hydroxide in HA powder within the HAC composites is important for bone grafting and bio-applications. 


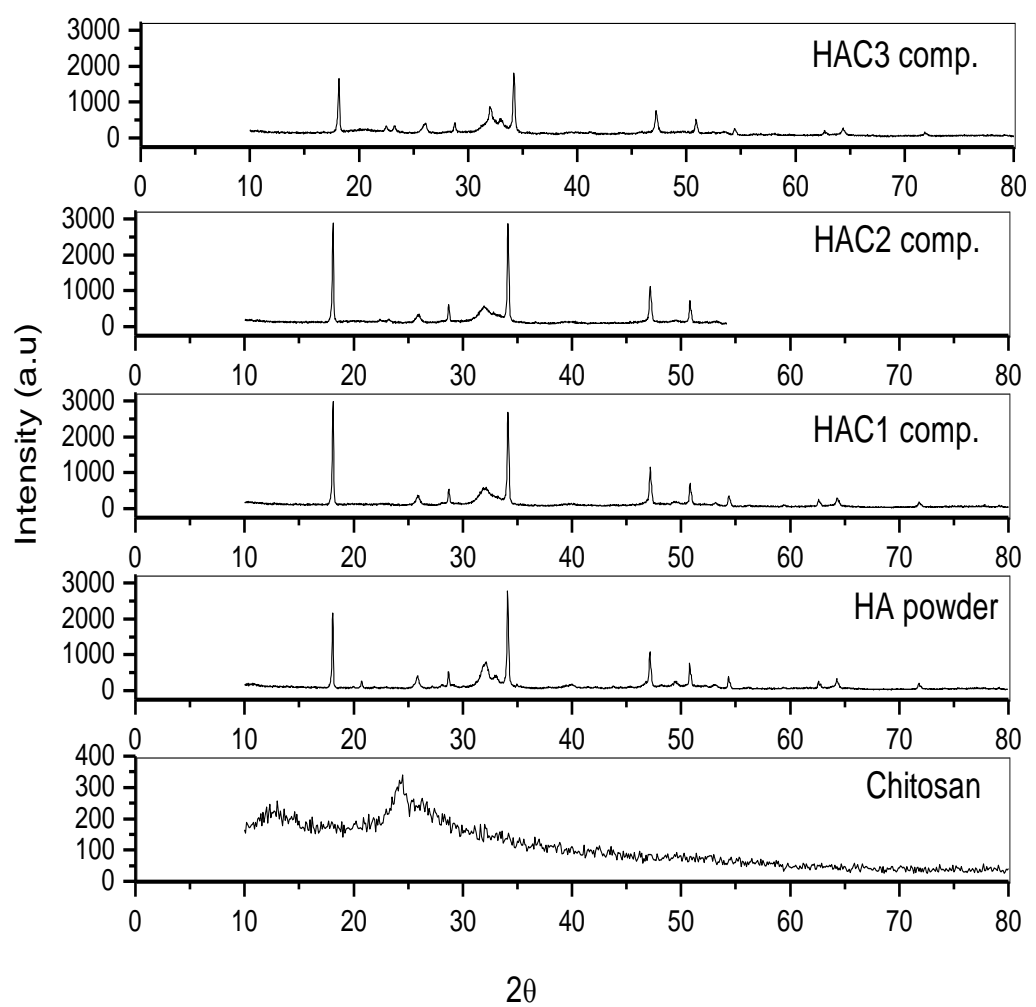

Fig. 3. The XRD of HA powder, chitosan and HAC composites .

The XRD patterns of HA, chitosan and HAC composites are shown in Fig. 3. The peaks of chitosan appeared at $2 \theta$ within the range of (20-30) and it has a hump peak because of its amorphous structure ${ }^{(13)}$. The intensity of all peaks of $\mathrm{HA}$ and calcium hydroxide in the HAC composites was reduced compared to those in HA powder, especially as in the HAC3 composite due to coating of HA particles by chitosan polymer. The broad peak of chitosan completely disappeared in three composites due to the effect of HA formation. Figure 4 shows the XRD patterns of HA, chitosan and their composites in the presence of citric acid. The main peak intensity of $\mathrm{HA}$ at $\mathrm{d}$-spacing $=2.8$ in the $\mathrm{HAC} 1 / \mathrm{citric}$ acid composite was gradually increased compared to the HA powder till reaching a maximum intensity in $\mathrm{HAC} 3 /$ citric acid composite denoting enhancement of HA formation as a result of the presence of citric acid. 


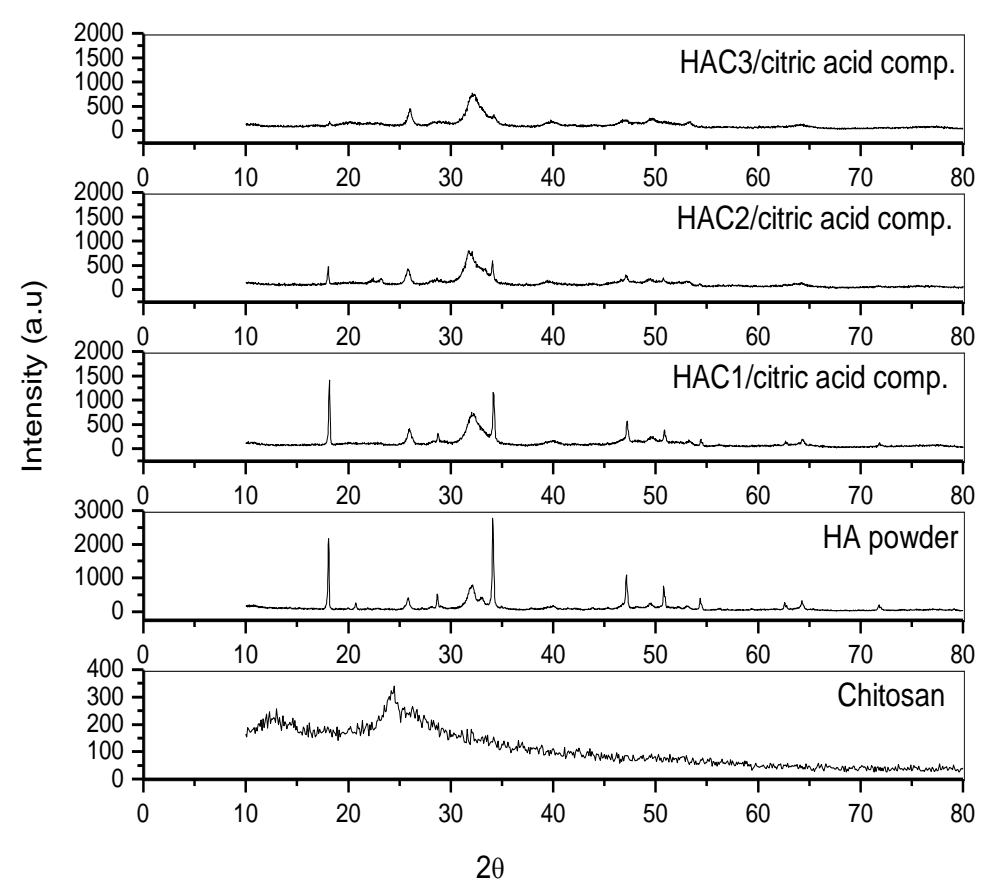

Fig. 4. The XRD of HA powder, chitosan and HAC/citric acid composites .

In this text, Shen et al. ${ }^{(12)}$ reported that citric acid has a strongly chelating ability of calcium ions to its carboxylate groups, furthermore, the presence of citric acid with high chitosan concentration, enhancing nucleation center for HA formation via $\mathrm{OH}-\& \mathrm{COO}^{-}$of citric acid and $\mathrm{OH}^{-} \& \mathrm{NH}_{3}{ }^{+}$of chitosan. While the peaks of citric acid appeared in HAC1/citric acid composite and their intensities were gradually reduced with increase of chitosan and completely disappeared as in HAC3/citric acid composite denoting high coating. By comparing Fig. 3 and Fig. 4 , it is noted that the intensity of HA peaks in the three HAC/citric acid composites is highly reduced compared to HAC composites denoting increase of coating by chitosan polymer on HA particles in the presence of citric acid.

\section{TGA analysis}

The TGA of HA powder and their $\mathrm{C}$ composites with chitosan polymer are shown in Fig. 5. The TGA analysis shows that the weight loss of $\mathrm{C}$ composites increased by increasing the chitosan content accompanying release of absorbed and structural water molecules, $\mathrm{NH}_{3}{ }^{+}$and $\mathrm{CO}_{2}$ gases. The weight losses of the HAC composites were 22.598, 26.598, and $29.801 \%$ in HAC1, HAC2 and HAC3 composites, respectively, due to gradual increase of chitosan content. These values were high compared to the HA (12.589\%) proving coating of chitosan polymer onto the HA particles. The TGA also revealed that the HAC composites are thermally stable above $600{ }^{\circ} \mathrm{C}$ due to the presence of HA phase so it is believed that chitosan was perfectly incorporated into the composites ${ }^{(2)}$. 


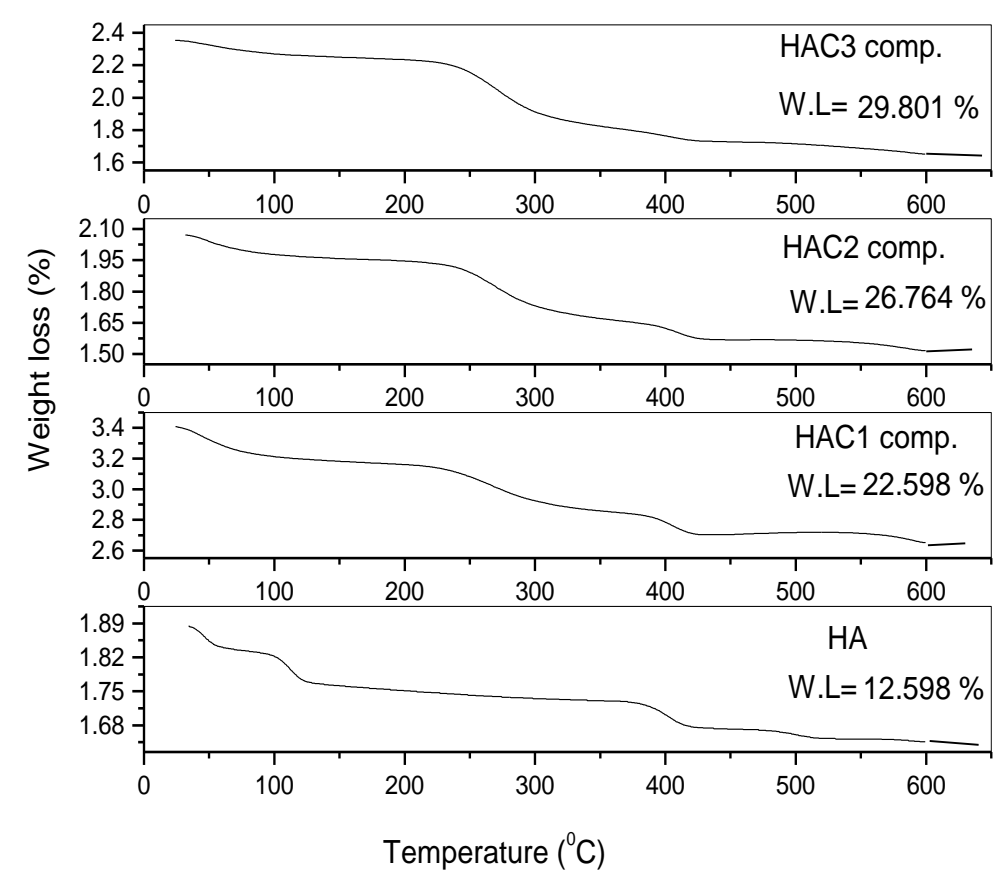

Fig. 5. The TGA of HA and its composites with chitosan polymer.

\section{Compressive strength}

Table 3 shows the changes in the compressive strength of the samples. It is obvious that the compressive strength was firstly increased with the increase of the chitosan content and reached a maximum value (19.6 MPa) for HAC2 composite. Afterwards, the compressive strength was decreased to (12.84 MPa) as in the HAC3 composite as a result of the reduction of interaction between two matrices. The values of compressive strength of all HAC composites were higher than that of the prepared HA $(9.66 \mathrm{MPa})$ proving the role of chitosan polymer matrix in enhancement of the bonding strength between the HA particles within the composite ${ }^{(14)}$. The compressive strength of the HAC/citric acid composites increased especially in the case of $\mathrm{HAC} 2 /$ citric acid composite recording 30.5 $\mathrm{MPa}$ in comparison with the HAC composites. The citric acid with $(0.2 \mathrm{M})$ concentration is good agreement to enhance the compressive strength of HAC composites because of the bonding strength which increased between HA particles with addition of citric acid ${ }^{(4)}$. 
TABLE 3. The compressive strength (MPa) of the prepared HA and its composites.

\begin{tabular}{|l|c|c|c|c|}
\hline Sample & $\begin{array}{c}\text { HA/chitosan } \\
\text { (Weight ratio) }\end{array}$ & HA & $\begin{array}{c}\text { HAC } \\
\text { composite }\end{array}$ & $\begin{array}{c}\text { HAC/citric acid } \\
\text { composite }\end{array}$ \\
\hline HA & $100 / 0$ & 9.66 & -- & -- \\
\hline HAC1 Comp. & $80 / 20$ & -- & 10.58 & 13.76 \\
\hline HAC2 Comp. & $70 / 30$ & -- & 19.6 & 30.5 \\
\hline HAC3 Comp. & $60 / 40$ & -- & 12.48 & 14.6 \\
\hline
\end{tabular}

\section{TEM photographs}

The TEM photographs of the prepared HA sample, HAC2 and HAC2/citric acid composite are shown in Fig.6 and Table 4. For HA powder, the crystallites are envisioned as needle and sphere-like in shape. The mean size of the needle is $7 \mathrm{~nm}$ in length and $5 \mathrm{~nm}$ in width. For HAC2 composite, the size of needle crystals was increased up to $38.66 \mathrm{~nm}$ in length and to $2.5 \mathrm{~nm}$ in width compared to that of the HA sample proving growth of HA crystals due to the presence of the chitosan polymer (Fig.6a and b). In this domain, the carbonate apatite in the nano level has an important impact on the cell biomaterials interaction because of its better resorption and close surface contact with the surrounding tissue ${ }^{(3)}$.

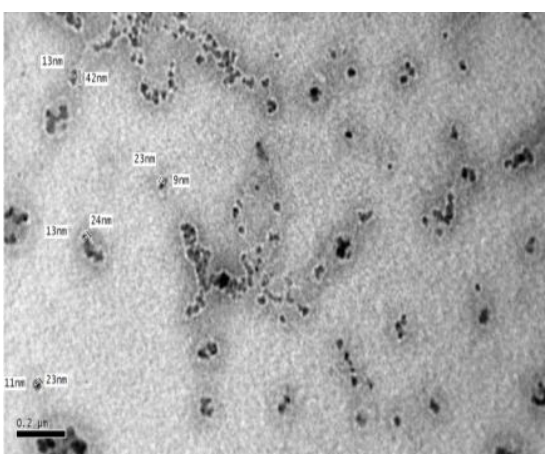

a

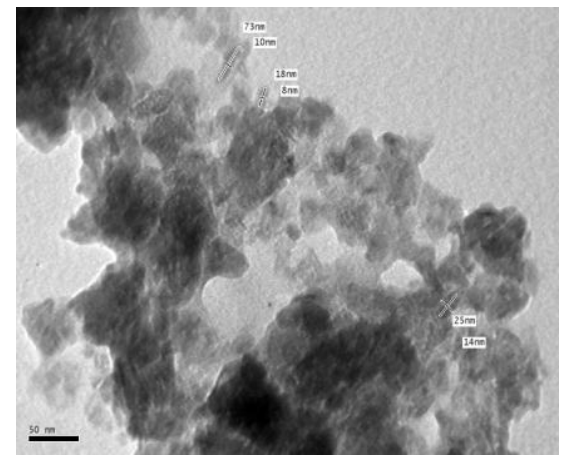

b

$\mathrm{c}$

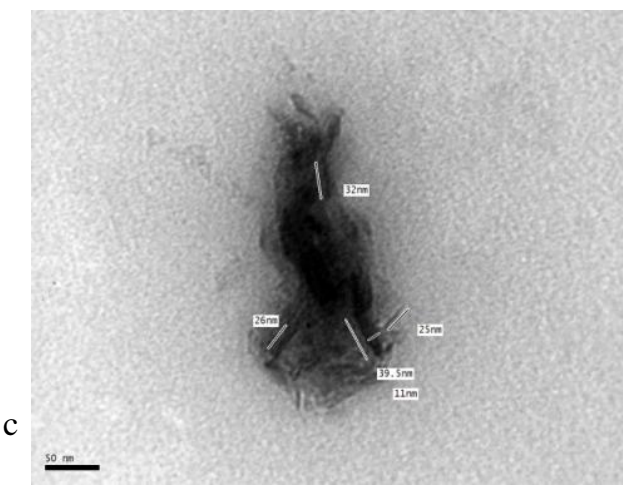

Fig. 6. The TEM images for (a) HA powder, (b) HAC2 composite and (c) HAC2/citric acid composite. 
For HAC2/citric acid composite, the TEM image shows nano-sized HA particles increase to $30.6 \mathrm{~nm}$ in length compared to HA sample (7nm) and they decreased compared to HAC2 composite $(38.66 \mathrm{~nm})$ (Fig.6c). This result may be caused by different intensities of interactions between ions with the addition of citric acid. The abundant supply of $\mathrm{COO}^{-}$coordination sites available for complexation with the $\mathrm{Ca}^{2+}$ ions produced a very large number of nuclei for the growth of nano-HA crystallites that were not able to grow largely ${ }^{(19)}$.

TABLE 4. The crystal size of ( $\mathrm{nm}$ ) of $\mathrm{HA}$ and its composites.

TABLE 4. The crystal size of (nm) of HA and its composites.
\begin{tabular}{|c|c|c|c|}
\hline Sample & HA powder & HAC2 composite & $\begin{array}{c}\text { HAC2/citric acid } \\
\text { composite }\end{array}$ \\
\hline Length $(\mathrm{nm})$ & 7 & 38.66 & 30.6 \\
\hline Width $(\mathrm{nm})$ & 2.8 & 10.66 & 8.34 \\
\hline
\end{tabular}

SEM morphology

Figure 7 shows the surface morphology of HAC2 and HAC2/citric acid composites. For the HAC2 composite, Fig.7a shows that the surface is rough due to the formation of HA particles in and onto the structure of chitosan polymeric matrix. Figure $7 \mathrm{~b}$ reveals that the surface is smooth, in which HA particles are uniformly dispersed into the chitosan matrix structure and were completely coated by the chitosan polymer proving integration. Regarding the SEM image of the HAC2/citric acid composite, the surface of the composite was smooth and there are many small spherical HA particles distributed, imbedded and coated within the composite structure denoting homogeneity and integration between the components of the composite (Fig.7c \& d). According to the SEM images, the HAC2/citric acid composite has high formation and nucleation of apatite compared with the HAC2 composite proving a vital role of citric acid in the acceleration of HA formation and its nucleation ${ }^{(20)}$.

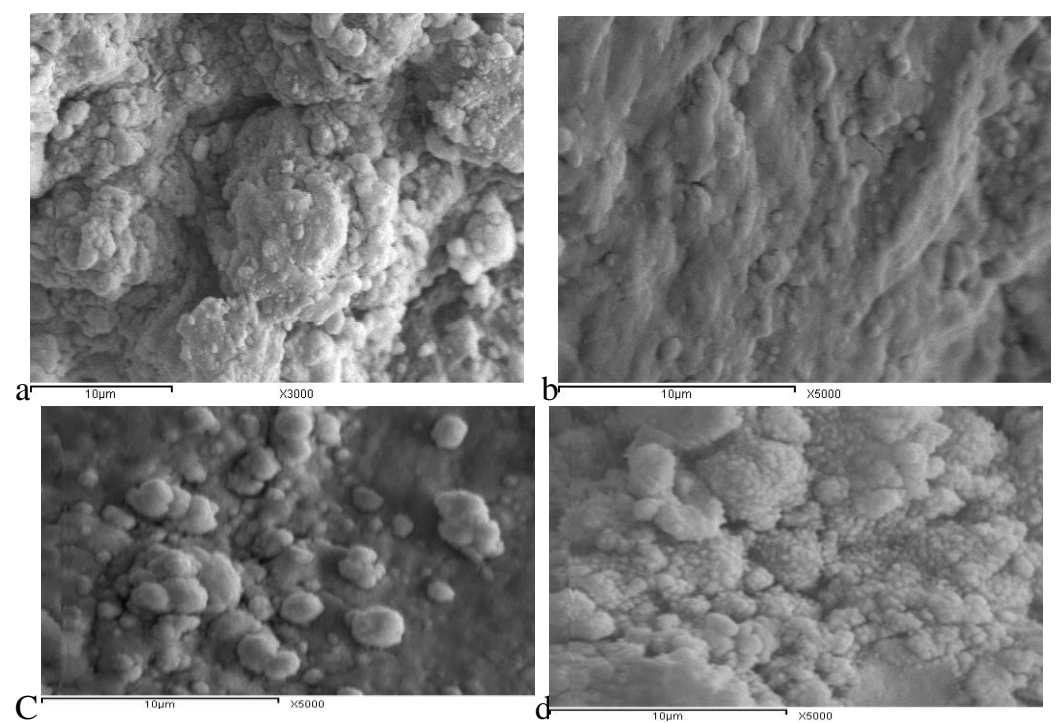

Fig. 7. The SEM images for (a, b) HAC2 composite and (c, d) HAC2/citric acid composite.

Egypt. J. Chem. 55, No. 1 (2012) 


\section{Conclusions}

The characterization of the samples proved that the formed HA was carbonated hydroxyapatite (CHA). The formation and coating of $\mathrm{CHA}$ particles increased by increasing the chitosan content and also were highly increased after the addition of citric acid. Also, the TEM data proved that the size of CHA particles had the nano-range scale and was increased in HAC2 composites proving the vital role of chitosan in the growth of HA particles but was decreased in HAC2/citric acid composite due to citric acid addition. The compressive strength increased with increasing the content of chitosan as in HAC2 composite and was highly increased as in HAC2/citric acid composite, because citric acid enhanced the binding strength between HA particles and chitosan polymer. The HAC composites with ratio $70 \% \mathrm{HA}$ and $30 \% \mathrm{C}$, especially with citric acid, are expected to be attractive for bone grafting and bone tissue engineering applications.

\section{References}

1. Jennifer, L.M. and Hockin, H.K., Mesenchymal stem cell proliferation and differentiation on an injectable calcium phosphate- chitosan composite scaffold. Biomaterials, 30 (14), 2675-2682 (2009).

2. Murugan, R. and Ramakrishna, S., Nano-structured biomaterials In: "Encyclopedia of Nanoscience and Nanotechnology", vol.7. pp. 595-613, H.S. Nalwa (Ed.) American Scientific Publishers, California (2004).

3. William, L.M. and David, J.M., Bioinspired growth of crystalline carbonates apatite on biodegradable polymer substrata. J. Am. Chem. Soc. 124,1910-7(2002) .

4. Yamaguchi, I., Iizuka, S., Osaka, A., Monma, H. and Tanaka, J., The effect of citric acid addition on chitosan hydroxyapatite composites. Colloids and Surfaces A: Physicochem. Eng. Aspects, 214, 111-118 (2003) .

5. Kim S.B., Kim, Y.J., Yoon, T.L., Park S.A., Cho, I.H., Kim, E.J., Kim, I.A. and Shin, J.W., The characteristics of a hydroxyapatite chitosan-PMMA bone cement. Biomaterials, 25, 5715-5723 (2004).

6. Kim, Y., Seo, S., Moon, H., Yoo, M., Park, I., Kim, B. and Cho, C., Chitosan and its derivatives for tissue engineering applications. Biotechnology Advances, 26, 1-21 (2008).

7. Martino, A.D., Sittinger, M. and Risbud, M.V., Chitosan: a versatile biopolymer for orthopedic tissue-engineering. Biomaterials, 26, 5983-5990 (2005).

8. Suh, J.K. and Matthew, H.W., Application of chitosan-based polysaccharide biomaterials in cartilage tissue engineering: a review. Biomaterials, 21 (24), 2589-98 (2000). 
9. Murugan, R. and Ramakrishna, S., Crystallographic study of Hydroxyapatite bioceramics derived from various sources. Cryst,, Growth Des. 5, 111-2 (2005).

10. Sivakumar, M. and Rao, K. P., Preparation, characterization and in vitro release of gentamicin from coralline hydroxyapatite-gelatin composites microsphers. Biomaterials, 23, 3175- 3181 (2002) .

11. Liuyun, J., Yubao, L., Zhang, L. and Jianguo, L., Preparation and properties of a novel bone repair composite: nano-hydroxyapatite/ chitosan/ carboxymethyl cellulose. J. Mater. Sci: Mater Med. 19, 981-987 (2008).

12. Shen, X., Tong, H., Jiang, T., Zhu, Z., Wan, P. and Hu, J., Homogeneous chitosan/carbonate apatite/citric acid nanocomposites prepared through a novel in situ precipitation method. Composites Science and Technology, 67, 2238-2245 (2007).

13. Mohamed, R.K., El- Bassyouni, G.T. and El- Beheri, H.H., Chitosan graft copolymer-HA/DBM biocomposites: Preparation, characterization and in-vitro evaluation. J. Applied Polymers Science, 105, 2553-2563 (2007).

14. Paleckiene, R., Sviklas, A. and Šlinkšiene, R., Reaction of urea with citric acid. Applied Chemistry, 78, No.10 (2005).

15. Zhang, L., Yubao, L., Apiing, Y., Xuelin, P., Xuejiang, W. and Xiang Z., Preparation and in vitro investigation of chitosan/ nano- hydroxyapatite composite used as bone substitute materials. Materials in Medicine, 16, 213-219 (2005).

16. Liang, Y., Wang J. and Yu, S., Mechanisms of bone repairment in periapical diseases: studies on adjusting bone metabolism with calcium hydroxide in vitro. Zhonghua Kou Qiang Yi Xue Za Zhi, 35, 112-114 (2000).

17. Evanov, C., Liewehr, F., Buxton, T.B. and Joyce, A.P., Antibacterial efficacy of calcium hydroxide and chlorhexidine gluconate irrigants at 37 degrees $\mathrm{C}$ and 46 degrees C. J. Endod, 30, 653-657 (2004) .

18. Charles, P., Nathalie, S., Carine, D. and Alexandru, G., Calcium hydroxide and treatment of inflammatory inter-radicular bone resorption of non-vital deciduous molars. Rev. Belge. Med. Dent. 59, 163-169 (2004).

19. Li, J., Chen, Y., Yin Y., Yao, F. and Yao, K., Modulation of nano-hydroxyapatite size via formation on chitosan-gelatin network film in situ. Biomaterials, 28, 781-790 (2007).

20. Sang-Hoon, R. and Junzo T., Hydroxyapatite formation on cellulose cloth induced by citric acid. Materials in Medicine, 11, 449- 452 (2000).

(Received 2/1/2011; accepted 9/4/2012) 


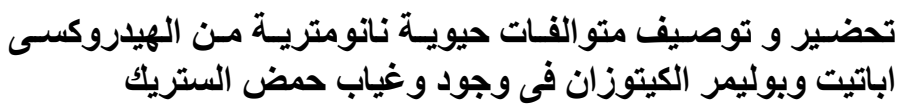

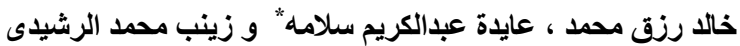

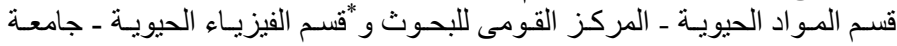

تم تحضبر متو الفات الحيوية من كربونات الاباتيت و بوليمر الكيتوز ان في وجود و وغياب

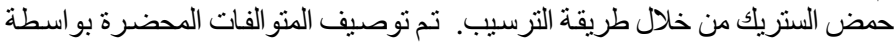

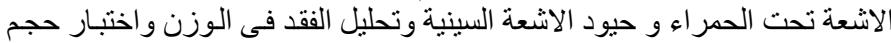

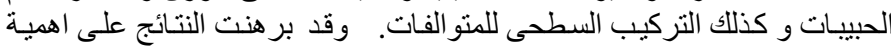

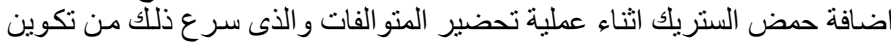

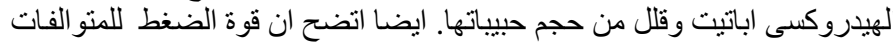

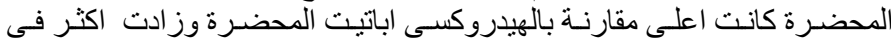

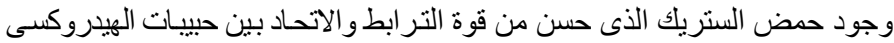

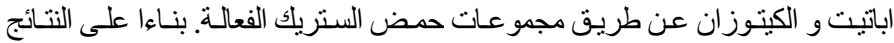

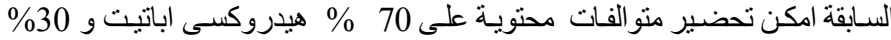

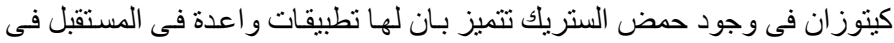
مجال استبدال العظام و هندسة الانسجة العظمية. 